\title{
Uma aplicação da teoria da língua em ato ao português do Brasil
}

\author{
An application of the Theory of Language in Act to \\ Brazilian Portuguese
}

\author{
Tommaso Raso \\ Heliana Mello \\ Andréa Ulisses Jesus \\ Luciano Alves de Deus \\ Universidade Federal de Minas Gerais
}

\begin{abstract}
In this article we present the first application of the theory of Language in Act (CRESTI, 2000b) to Brazilian Portuguese. After a summary of the theory is presented, we show how a text can be divided in utterances and how the utterance can be divided in tone units, through the perception of terminal and non terminal prosodic breaks. Based on dedicated entonational profiles, we show the informational tagging of the tone units, which is motivated by prosodic, functional and distributional criteria. We conclude by showing how the prosodic and informational frame clearly change, depending on turn size and evidence of the illocutionary principle.
\end{abstract}

Keywords

Theory of Language in Act; Brazilian Portuguse; Information units

\section{Resumo}

Neste artigo, apresenta-se a primeira aplicação da teoria da língua em ato (CRESTI, 2000b) ao português do Brasil. Apresenta-se um resumo da teoria e a seguir mostra-se como um texto é segmentado 
em enunciados e como o enunciado é segmentado em unidades tonais, graças à percepção de quebras prosódicas terminais e não terminais. Com base em perfis entonacionais dedicados, atribui-se a cada unidade tonal uma etiqueta informacional, motivada por critérios prosódicos, funcionais e distribucionais. Na conclusão, mostra-se como o quadro prosódico e informacional muda claramente, dependendo do tamanho dos turnos dialógicos e da evidência do princípio ilocucionário.

\section{Palavras-chave}

Teoria da Língua em Ato; Português brasileiro; Unidades informacionais 


\begin{abstract}
A presentamos aqui a primeira aplicação da teoria da língua em ato ao $A$ português do Brasil, a qual foi elaborada por Cresti (2000a, b ) e 1 aplicada primeiramente ao italiano (CRESTI, 2000b) e sucessivamente às quatro principais línguas românicas da Europa: italiano, francês, espanhol e português europeu (CRESTI; MONEGLIA, 2005). ${ }^{1}$
\end{abstract}

\title{
1. Os princípios base
}

A teoria se baseia na individualização da correspondência entre unidade de ação, ou seja, o ato de fala (AUSTIN, 1962), e unidade lingüística, o enunciado, através de parâmetros entonacionais. Isso permite a segmentação do discurso em unidades mínimas, os enunciados, cada uma capaz de veicular uma ilocução, ou seja, uma unidade do domínio da ação. O enunciado (ato locutório), então, é visto como a contraparte linguística do ato de fala (ato ilocutório), e se define como a unidade, mínima interpretável pragmaticamente. ${ }^{2} \mathrm{~A}$ identificação do enunciado é possível através da percepção de um perfil entonacional com valor terminal. Com base na teoria fonética perceptual (T'HART; COLLIER; COHEN, 1990), a teoria da língua em ato assume que o interlocutor percebe o perfil terminal como uma instrução de que um determinado enunciado e, portanto, uma ação lingüística, esteja cumprida. Disso resulta, então, uma relação biunívoca entre enunciado e ilocução; a cada enunciado, ou seja, a cada unidade textual mínima, corresponde uma e somente uma ilocução, isto é, uma intenção comunicativa do falante.

O enunciado, por sua vez, pode ser simples - executado em uma única unidade tonal - ou pode ser complexo, isto é, executado em mais unidades tonais. Cada unidade tonal veicula uma unidade informacional. Dentro do enunciado existe, portanto, uma correspondência biunívoca entre unidade tonal e unidade informacional: a cada unidade tonal corresponde unicamente uma unidade informacional. A teoria assume que o interlocutor percebe as fronteiras entre as unidades tonais graças à percepção de um perfil entonacional não terminal. 
Assim, é necessário distinguir entre perfis entonacionais terminais, que sinalizam a conclusão de um enunciado, e perfis entonacionais não terminais, que sinalizam o fim de uma unidade tonal interna ao enunciado. ${ }^{3}$

Somente um tipo de unidade informacional é obrigatória (enunciados simples), porque veicula a força ilocucionária; ${ }^{4}$ as outras são opcionais e possuem várias funções, como esclareceremos adiante. Dessa forma, os enunciados simples são aqueles formados unicamente por unidades informacionais de comentário, ou seja, as unidades que veiculam a força ilocucionária (CRESTI, 2000a, b, p. 77-116; CRESTI; MARTIN; MONEGLIA, 1998), enquanto os enunciados complexos, além da unidade de comentário, possuem uma ou mais unidades, cuja função não é aquela de veicular a força ilocucionária, mas uma outra função. $\mathrm{O}$ mesmo conteúdo locutivo, por exemplo, João me ligou ontem, pode assim ser executado de maneiras diferentes, com diferentes padrões entonacionais e, conseqüentemente, veicular diferentes estruturas informacionais. A seguir, exemplificam-se três possibilidades, que não podem ser consideradas sinônimas:

1. João me ligou ontem $/ /{ }^{5} \mathrm{O}$ enunciado (FIG. 1$)^{6}$ é executado em uma única unidade tonal, correspondente, portanto, a uma unidade informacional de comentário, necessária e suficiente para veicular a força ilocucionária. Um possível contexto em que essa execução seria apropriada é o seguinte:

A: Recebeu alguma notícia dos amigos que estão na praia?

\section{B: João me ligou ontem.}

2. João/me ligou ontem//. Nesse exemplo, o enunciado (FIG. 2) seria executado através de duas unidades tonais, uma de tópico e uma de comentário. Um possível contexto em que essa execução seria apropriada é o seguinte:

A: Você tem notícias do João?

B: João / me ligou ontem.

3. JOÃO / me ligou ontem//. Aqui as maiúsculas em JOÃO tentam imitar a proeminência entonacional. Aqui também (FIG. 3) temos duas unidades entonacionais e, portanto, duas unidades informacionais; mas, contrariamente ao exemplo 2, aqui a primeira unidade é uma unidade de comentário e a segunda, uma unidade de apêndice. Um possível contexto em que essa execução seria apropriada é o seguinte:
A: Quem te ligou ontem?
B: João / me ligou ontem. 


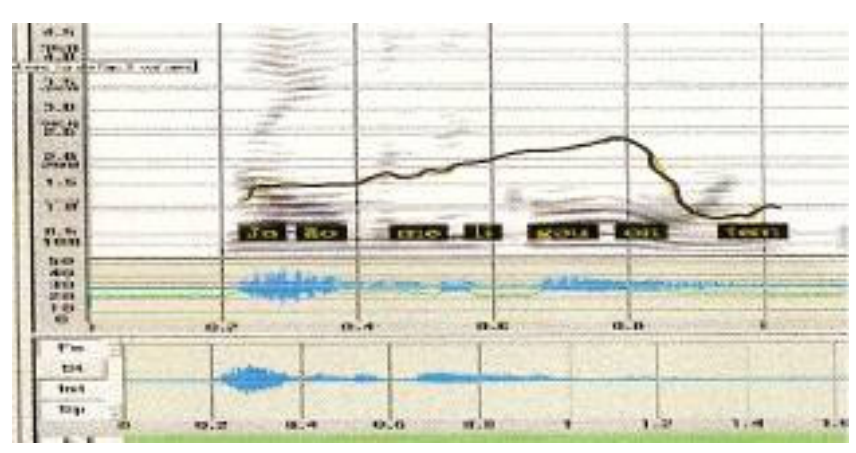

FIGURA 1 - João me ligou ontem//

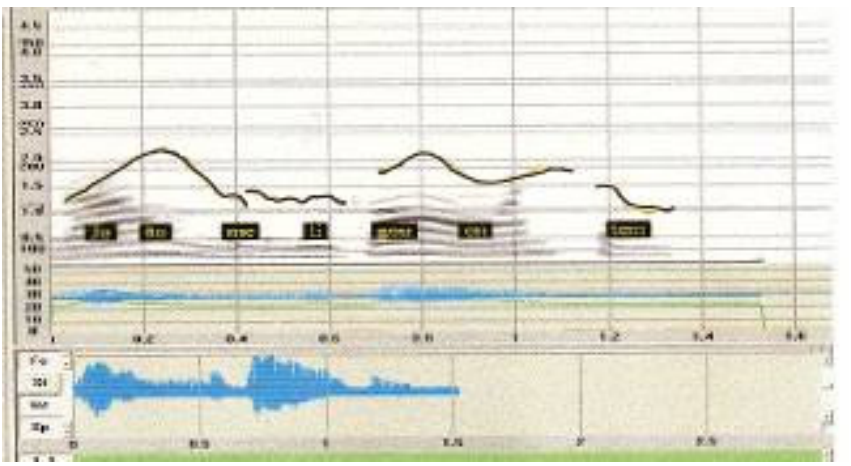

FIGURA 2 - João / me ligou ontem//

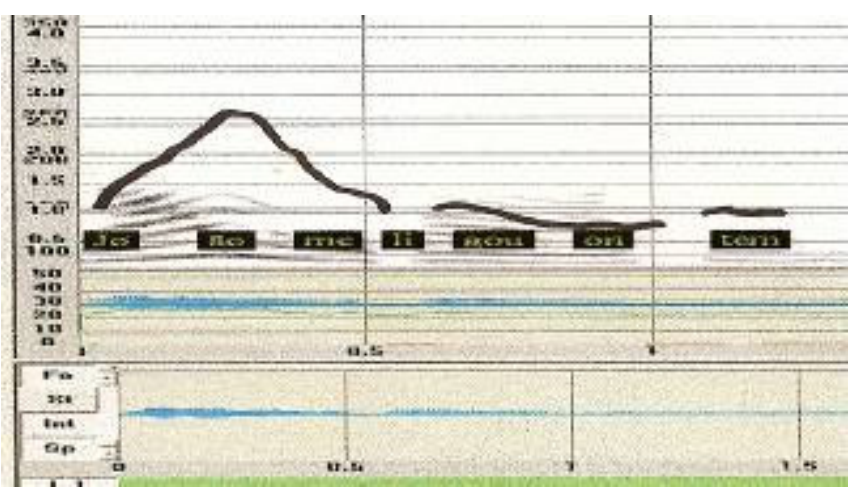

FIGURA 3 - JOÃO / me ligou ontem// 
Vimos assim a execução de três enunciados com um mesmo conteúdo locutivo, mas realizados com diferentes funções informacionais, veiculadas por estruturas entonacionais diversas: um enunciado simples (FIG 1), um enunciado complexo com estrutura tópico-comentário (FIG. 2) e um enunciado complexo com estrutura comentário-apêndice (FIG. 3). A curva entonacional mostra claramente a diferença entre os três. A percepção do interlocutor permite a identificação da função informacional através do diferente perfil de cada perfil entonacional. ${ }^{7}$

Ao mesmo tempo em que identificamos um enunciado como simples ou complexo e, se for complexo, identificamos também as diferentes funções informacionais das várias unidades tonais, podemos também identificar o tipo de força ilocucionária veiculada pela unidade de comentário. A força ilocucionária também independe do conteúdo locutivo: podemos ter o mesmo conteúdo locutivo realizado de maneira a veicular diferentes ilocuções, assim como podemos ter diferentes conteúdos locutivos realizados de maneira a veicular a mesma ilocução. Por exemplo, um conteúdo locutivo como João pode ser realizado, entre outras possibilidades, para chamar alguém que tenha esse nome (FIG. 4), para responder à pergunta Quem te ligou ontem? (FIG. 5), para expressar surpresa encontrando uma pessoa que não se via há anos e que tenha esse nome (FIG. 6). Naturalmente, cada uma dessas ilocuções pode ser expressa com conteúdos locutivos diferentes. O que conta aqui é que a curva entonacional permite ao interlocutor identificar a intenção com que um determinado conteúdo locutivo é realizado. O interlocutor não atribui valor funcional às diferenças microprosódicas que deiferenciam a curva de dois conteúdos locutivos diferentes com a mesma força ilocucionária, mas somente às diferenças de ilocuções diferentes, não importando se elas são caracterizadas pelo mesmo conteúdo locutivo. ${ }^{8}$

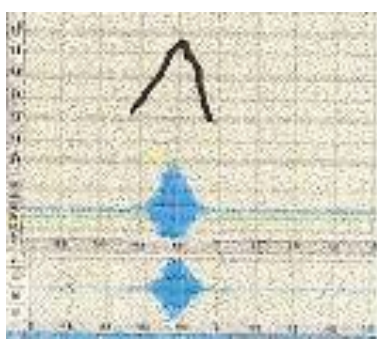

FIGURA 4 - JOÃO (chamada)

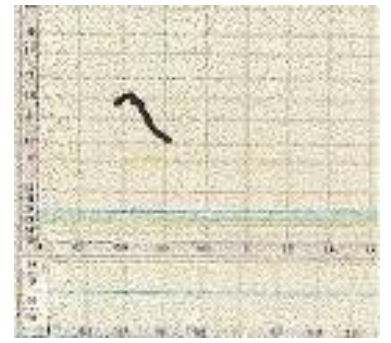

FIGURA 5 - JOÃO (resposta)

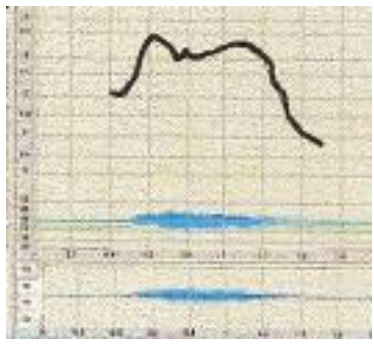

FIGURA 6 - JOÃO (surpresa) 


\section{As unidades informacionais}

Na seção 1 foram nomeadas três unidades informacionais distintas: o comentário (C), o tópico (T) e a apêndice (AP). Essas três unidades não são as únicas possíveis, mas são as mais importantes, pois são aquelas que compõem o texto propriamente dito. Cada uma delas tem um ou mais perfis entonacionais dedicados, ou seja, tem perfis entonacionais próprios, que permitem ao interlocutor perceber a função informacional através de uma entonação que identifica essa função.

O C é a unidade mais importante de todas, pois é a única necessária e suficiente para formar um enunciado, enquanto carrega a força ilocucionária, ou seja, cumpre $o$ ato de fala, veiculando a intenção comunicativa. O T se define como o campo de aplicação da força ilocucionária; no enunciado 2, João / me ligou ontem, a força ilocucionária de resposta se aplica ao campo constituído por João. ${ }^{9}$ AP constitui uma integração textual da unidade que antecede; no enunciado 3, me ligou ontem é uma integração textual da força ilocucionária carregada pela unidade de comentário JOÃO . Podemos, portanto, ter AP de comentário (APC), como no exemplo acima, e AP de tópico (APT), quando a integração textual se refere a uma unidade de tópico. Um exemplo desse último tipo poderia ser, modificando o exemplo 2 sem mudar o contexto e o perfil das outras unidades: João Batista / Campos / me ligou ontem (FIG. 7). A segunda unidade seria uma APT, integrando textualmente a unidade de tópico.

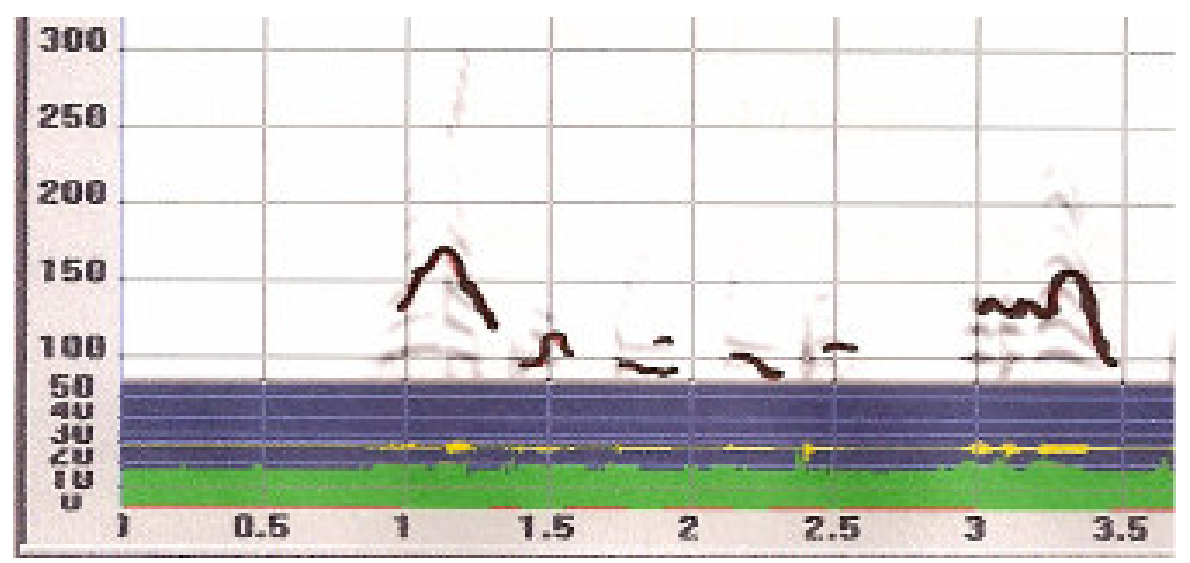

FIGURA 7 - João Batista / Campos / me ligou ontem // 
Sem ainda sair dessas três unidades, podemos notar que, para descrever o comentário, o tópico e o apêndice, usamos critérios diferentes: um critério entonacional, pois observamos que cada unidade possui um ou mais perfis dedicados; um critério funcional, pois notamos que o comentário tem a função de carregar a força ilocucionária, o tópico a função de estabelecer o campo de aplicação dessa força e o apêndice a função de integrar textualmente as outras duas unidades. Um terceiro critério, que não usamos ainda explicitamente, é o critério distribucional: o comentário não possui uma posição fixa, podendo inclusive ser a única unidade do enunciado; o tópico precisa inevitavelmente estar posicionado antes do comentário, mesmo se, como veremos, não necessariamente em posição inicial de enunciado; o apêndice precisa ocupar a posição após a unidade da qual é apêndice, ou seja, o tópico (e então teremos um apêndice de tópico - APT) ou o comentário (e então teremos um apêndice de comentário APC). São, portanto, esses três critérios que definem as unidades informacionais: 1. critério entonacional; 2 . critério funcional; 3 . critério distribucional.

Já mencionamos que, além dessas três unidades informacionais (C, TeAP), outras unidades podem participar da composição do enunciado. Elas são: 1. os auxílios dialógicos (AUX); 2. os incisos (INX); e 3. os introdutores locutivos (INTL).

Os auxílios dialógicos (CRESTI, 2000b, p.137-143) se dividem, por sua vez, em pelo menos quatro tipos (nas duas interações, achamos exemplos dos primeiros dois tipos): 1.os incipitários (INP); 2. os fáticos (FAT); 3. os alocutivos (ALC); e 4. os conativos (CON). Na fala, muito frequientemente, temos enunciados constituídos por unidades de comentário e uma outra unidade, sendo que essa não tem nem a função de delimitar o campo de aplicação da força ilocucionária nem aquela de integração locutiva. Essa unidade parece ter uma força ilocucionária muito fraca de tipo diretivo, insuficiente para que seja interpretável em isolamento, e locutivamente pode ter conteúdos muito variados, normalmente resumidos na categoria dos marcadores discursivos. Também as unidades de auxílio dialógico possuem um perfil entonacional próprio. Elas não têm uma relação com o conteúdo locutivo do enunciado, mas sim com o interlocutor ou com a própria locução. As funções são de: sinalizar a tomada de turno (incipitários), com uma colocação normalmente em começo de enunciado; controlar o bom funcionamento da comunicação e a abertura do canal (fáticos), podendo ocorrer em qualquer posição; controlar a comunicação através de uma alocução direta ao participante (alocutivos) graças a um nome, um título, um pronome, ${ }^{10}$ colocandose normalmente em princípio de enunciado; pressionar o interlocutor para que 
faça algo ou desista de algo ou mude o comportamento (conativos), ocorrendo normalmente em final de enunciado. ${ }^{11}$

Os incisos (FIRENZUOLI; TUCCI, 2003 e TUCCI, no prelo), também com um perfil dedicado, têm uma função metalingüística, permitindo ao falante comentar o conteúdo da própria locução saindo do ponto de vista interno ao enunciado (alguns incisos estão presentes na interação 2). Eles não participam da composição textual do enunciado, mas constituem uma interpretação ou uma instrução direta ao interlocutor. Retomando o nosso exemplo 2 , teríamos um inciso na segunda unidade se o exemplo fosse modificado assim: João/confesso /me ligou ontem (FIG. 8). A disposição dos incisos é interna ao enunciado, e pode ocorrer até dentro de uma unidade de comentário, tópico e apêndice, ou em fim de enunciado. Os incisos são caracterizados também por um abaixamento da $\mathrm{F}_{0}$ e um aumento da velocidade de elocução.

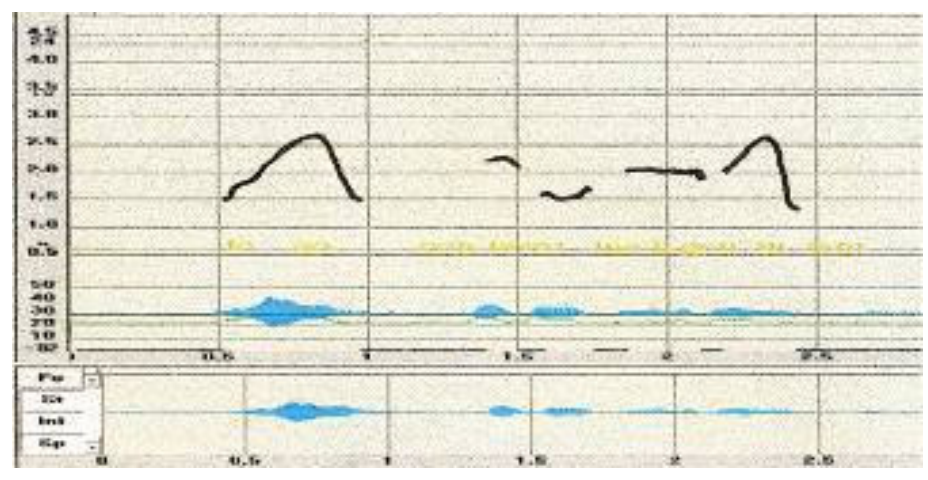

FIGURA 8 - João / confesso / me ligou ontem//

Os introdutores locutivos têm a função de sinalizar o discurso direto citado ou de introduzir os comentários complexos, dos quais se falará mais à frente e, como todas as unidades informacionais, possuem um perfil entonacional próprio. Esse perfil pode variar, mas tem sempre duas características constantes: não possui um movimento que possa funcionar como foco, e apresenta uma $\mathrm{F}_{0}$ mais baixa que a normal do falante, de maneira que seja ressaltada a elevação de $\mathrm{F}_{0}$ e a estilização dos comentários de citação. A colocação do introdutor locutivo é sempre antes de um comentário complexo (como é o caso do discurso direto de citação), e funcionalmente se define como um aviso de que o que vem na sequiência não deve ser interpretado autonomamente, mas sim dentro de uma 
ilocução maior, ou seja, aquilo que segue retoma coordenadas espaço-temporais que não são aquelas do hic et nunc, mas sim aquelas em que originariamente foi pronunciado. Um exemplo evidente é o primeiro enunciado da interação 1: que que cê leva em consideração // quando ela fala assim / trabalhe em pares. Nesse enunciado, a ilocução primária é de pergunta, dada na primeira unidade de comentário (FIG. 9); a segunda unidade é um introdutor locutivo que introduz a citação (FIG. 10); a citação (trabalhe em pares) é claramente estilizada e possui uma $\mathrm{F}_{0}$ mais alta, como sinal da própria dependência (FIG. 11); ao mesmo tempo, o introdutor (quando ela fala assim) tem uma $\mathrm{F}_{0}$ mais baixa. ${ }^{12}$

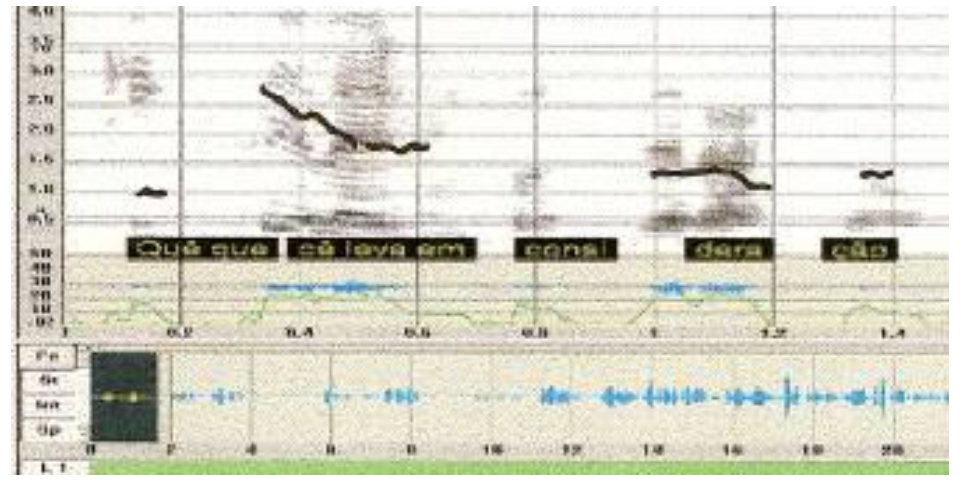

FIGURA 9 - o que cê leva em consideração /

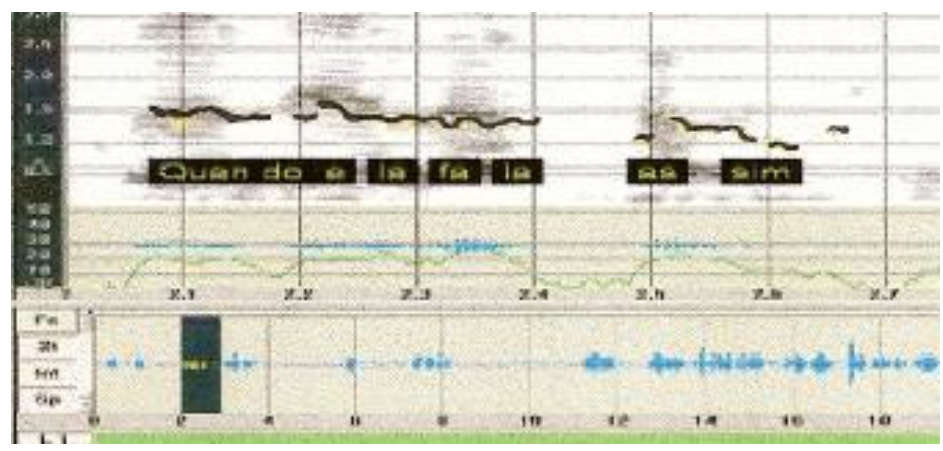

FIGURA 10 - quando ela fala assim / 


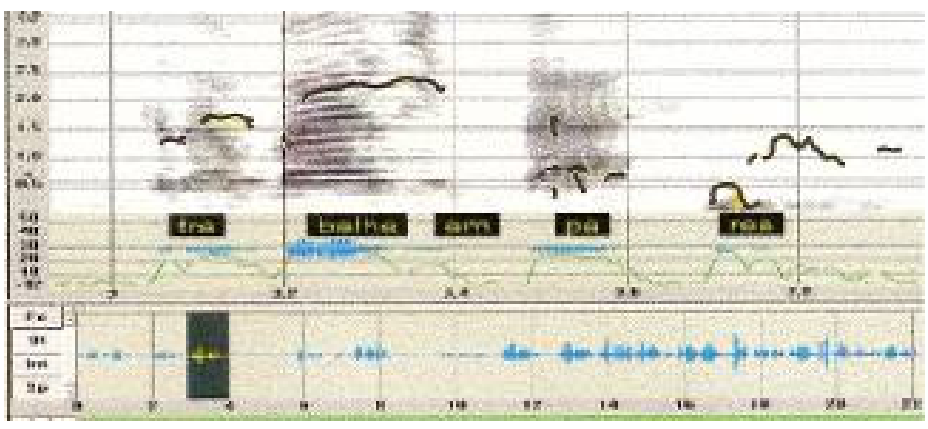

FIGURA 11 - trabalhe em pares//

\section{Quando a correspondência não é biunívoca}

Na seção 1 falamos que sempre existe um isomorfismo entre unidade tonal e unidade informacional, que estariam sempre em correspondência biunívoca. Também falamos que existe correspondência biunívoca entre comentário e enunciado, ou seja, que cada enunciado possui sempre uma e somente uma unidade de comentário. Chegou a hora de problematizar essas afirmações (CRESTI, 2000b, p.145-166). Antes disso, porém, é preciso reafirmar que esse isomorfismo é o fundamento de qualquer fala espontânea, mesmo se em qualquer texto for possível produzir segmentos de fala em que o isomorfismo se perde. Um primeiro caso é quando uma unidade informacional, principalmente o comentário, é fracionada em mais unidades tonais. Se, por alguma razão, um falante se encontra em dificuldade, pode não conseguir realizar o que tinha programado. Isso pode acontecer também nos casos em que o programa melódico da unidade tonal seja longo demais em número de sílabas, e o falante, então, precise distribuir a unidade informacional em mais unidades tonais. Assim, quando a locução é extensa ou por alguma razão problemática, o falante produz unidades de uma palavra ou sintagma, dando a elas uma entonação neutra, e repetindo esse mecanismo até completar a expressão, realizando apenas na parte final o perfil desejado do ponto de vista funcional.

Um segundo caso, já mencionado em 2, é o dos comentários múltiplos. Esse caso é bem diferente do anterior, já que aqui não se respeita o princípio segundo o qual em cada enunciado existe um único comentário com valor ilocucionário. Existem de fato algumas ilocuções específicas em que em um único enunciado estão presentes duas ou mais unidades de comentário. A esse respeito 
já falamos da ilocução de citação, na qual uma ilocução, cujo ponto de vista não pertence às coordenadas espaço-temporais do enunciado, é inserida dentro dele. Há outros três tipos de ilocuções que se distribuem necessariamente em mais unidades de comentário: 1. a ilocução de elenco, em que cada elemento do elenco se coloca numa unidade de comentário diferente (um exemplo na interação 2); 2. a ilocução de comparação, em que cada elemento da comparação ocupa uma unidade de comentário; 3 . a ilocução de hipótese ou relação de necessidade. ${ }^{13}$

Esse último caso merece uma explicação mais aprofundada. Na fala, o tipo de relação existente entre os dois membros de um período hipotético se realiza muitas vezes de maneira diferente do que acontece na escrita. Essa relação pode ser realizada com uma estrutura tópico-comentário, mas também foram identificados casos com dois comentários (um assertivo fraco e outro assertivo forte ou diretivo) sem nenhum operador morfo-sintático ou lexical, mas unicamente graças à gradação entonacional. Todavia, essa relação possui um valor semântico mais amplo do que aquele do período hipotético, refletindo uma relação especialmente estreita e necessária entre os dois comentários, seja ela de natureza temporal ou de semelhança, e não de natureza lógica ou de causaefeito como no período hipotético. ${ }^{14}$ Um comentário de asserção fraca é o que caracteriza também um tipo particular de auxílio dialógico, as chamadas tag questions, como não é?, não acha?, né? em final de enunciado (veja-se a FIG. 12).

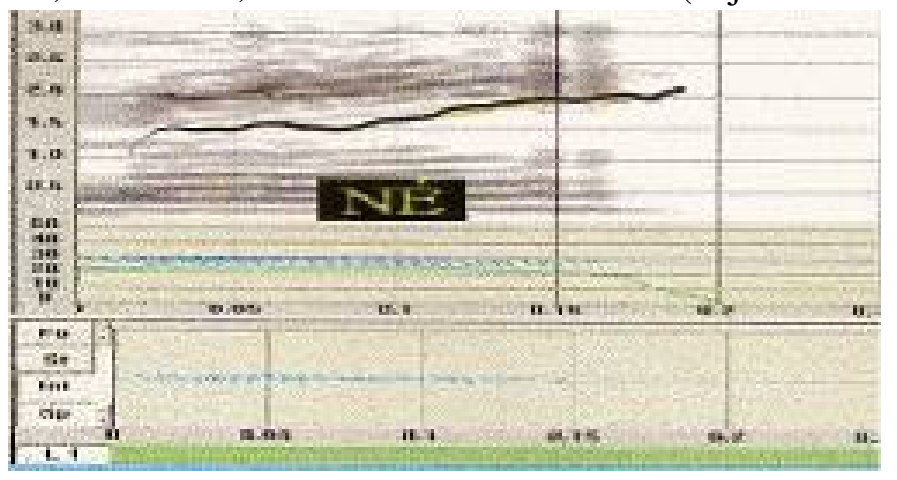

FIGURA 12 - Um perfil de tag question retirado da interação 2

*FBA: cê sentir que o aluno pelo menos num tá morto / em relação a língua / né // 
Um terceiro caso em que o isomorfismo se perde é no que poderia ser chamado de "estrofe" (CRESTI, 2000b, p. 162-164). Em alguns textos, com menor ou maior constância, desaparece tanto a correspondência entre unidade tonal e unidade informacional, quanto aquela entre enunciado e um comentário único, já que se perde a estruturação ilocucionária do enunciado. Acontecem, portanto, dois fenômenos diferentes: a sequência de mais comentários com o mesmo valor ilocucionário, mas reconhecíveis com menos clareza (comentários ligados); a construção retórica de um texto locutivo comprido e que use estratégias várias. Isso acontece quando o texto perde a espontaneidade típica da interação livre entre os interlocutores. O princípio ilocucionário é de fato ligado a uma interação imediata, em que a atividade verbal é direcionada imediatamente ao interlocutor e às suas reações. ${ }^{15}$ Quando essa condição se enfraquece, tipicamente em textos monológicos e regrados, ainda mais em diastratia culta, a segmentação do texto não é finalizada somente ou prevalentemente à transmissão de uma ilocução ou de estruturas informacionais, mas é organizada com base em princípios retóricos e argumentativos. Nessas circunstâncias, a entonação se torna um instrumento desses princípios, reduzindo ou abandonando as funções ilocucionária e informacional. Estamos então num uso da oralidade que apresenta já muitos pontos de contato com a escrita, posto que o princípioguia do enunciado e do ato ilocucionário cede, em parte ou totalmente, o campo a longas sequiências locutivas organizadas com base semântica. Às vezes, a passagem de um critério ilocucionário para um critério baseado na estrofe acontece dentro do mesmo texto, permitindo assim a identificação do momento em que se abandona uma coloquialidade espontânea e baseada na ação sobre o interlocutor para estratégias que concentram a atenção na construção da locução (tipicamente em longos trechos narrativos, expositivos ou argumentativos). Essa passagem se traduz, portanto, em fenômenos objetivos e mensuráveis.

Ainda diferente é o que acontece em muitos textos caracterizados por serem transmitidos em diamesias específicas, como o rádio ou a televisão, tipicamente textos publicitários, ou de locutores profissionais em condições específicas (como DJs ou locutores de futebol). ${ }^{16} \mathrm{Nesses}$ casos, o texto prescinde quase totalmente da interação entre falante e interlocutor, e atua uma interação entre emitente e audience. A entonação assume mais a função de reconhecimento do emitente e se estrutura com base em picos abnormes, se comparados com o que acontece na fala espontânea, e principalmente em parâmetros rítmicos, que se tornam o traço mais importante para reconhecer a fonte do som. 


\section{Contexto e participantes}

A seguir, apresentamos dois excertos de transcrição de duas interações dialógicas gravadas em 2005. Em ambas, o pesquisador formula perguntas aos entrevistados e os dois discursam sobre o processo de ensino/aprendizagem de inglês como língua estrangeira em escolas públicas. As diferenças são relativas às características dos informantes e à estrutura do diálogo. Essas interações foram gravadas em cabine acústica do Laboratório de Fonética da UFMG, com o objetivo de garantir a qualidade acústica do material coletado. Apesar de terem sido gravadas em cabine acústica, as interações devem ser consideradas como fala espontânea, uma vez que não houve nenhuma programação ou preparo anterior (CRESTI; SCARANO, 2000).

Na interção 1, oinformante (Gabriel) ${ }^{17}$ é um aluno de 14 anos de idade, aluno do ensino fundamental da rede pública de ensino e estuda inglês há 3 anos. Gabriel, em turnos muito curtos, expressa opiniões sobre o próprio processo de aprendizagem. Os turnos breves das intervenções de Gabriel motivam a forte presença do pesquisador (Vitor), autor também de turnos breves, geralmente de perguntas.

A interação 2, por sua vez, versou sobre a adoção de uma metodologia de pesquisa denominada "pesquisa-ação colaborativa”" (BURNS, 1999), que visa ao desenvolvimento profissional dos envolvidos na implementação da mesma. A cada ação desenvolvida para implementação dessa abordagem, realizaram-se sessões de visionamento nas quais a pesquisadora (Adriana) e a informante de pesquisa (Fabiola) analisavam os resultados obtidos. As interações, embora dialógicas, tendem ao discurso monológico em turnos longos com seqüências narrativas e argumentativas, dada a complexidade de articulação da informação apresentada pela informante Fabiola (a interação 2 diz respeito a apenas metade de um turno). Fabíola é graduada em Letras por uma universidade pública do estado de Minas Gerais, é professora de inglês do ensino fundamental, tem 30 anos de idade e pouco menos de dois anos de experiência de ensino em escola pública.

Os trechos apresentados possuem respectivamente 23 e 46 segundos de duração, com um total de 50 palavras produzidas por Gabriel e 129 palavras produzidas por Fabíola, totalizando 179 palavras. Os dois textos foram escolhidos para mostrar algumas diferenças na segmentação e na etiquetagem entre turnos breves e turnos longos em interações dialógicas. 


\section{Segmentação e etiquetagem prosódica dos enunciados ${ }^{18}$}

Os códigos utilizados para transcrição são:

\begin{tabular}{|ll|}
\hline$/ /$ & Quebra prosódica terminal (limite do enunciado) \\
$?$ & Quebra prosódica terminal (limite do enunciado) \\
{$[/]$} & Quebra prosódica não-terminal causada por um falso começo \\
{$[/ /]$} & Quebra prosódica não-terminal por um retraimento (retracting) com \\
& repetição ou não do material lingüístico \\
$<>$ & Sobreposição \\
hhh & Elementos paralingüísticos (riso, choro, etc) \\
\hline
\end{tabular}

\section{Interação 1}

VTR: que que cê leva em consideração /// ${ }^{\mathrm{COM}}$ quando ela fala assim /NTL trabalhe em pares // $\mathrm{COM}$

GBL: $\quad$ ah / INP tem dia que enche o saco //COM hhh tem dia que enche mesmo //COM porque $<$ as $>[/]$

VTR: $\quad<$ trabalhar $>$ junto? ${ }^{\text {com }}$

GBL: não //COM

VTR: $\quad$ você fala $/ /^{\mathrm{TOP}}<\mathrm{o}$ quê $/$ COM que enche o saco $>/ /^{\mathrm{APC}}$

GBL: $\quad<e ́ /$ /NP porque tem dia /TOP que cê está $>$ com mais $\mathrm{m}[/ /]^{\mathrm{COM}}$ com mau humor // $\mathrm{com}$

VTR: $\quad$ hum hum //COM

\section{Interação 2}

Sim //COM bastante positivo //COM eu /TOP já até [/] já tinha falado [/] $]^{\mathrm{INX}}$ né / / FAT mencionado isso com você anteriormente / /NX/eh / eu senti / TOP / eh / em muitos alunos $[/]^{\mathrm{TOP}}$ né $/{ }^{\mathrm{FAT}}$ eu notei / /OP em vários alunos $/{ }^{\mathrm{TOP}}$ assim $/ /^{\mathrm{INX}}$ reações $/{ }^{\mathrm{COM}}$ que eu não tinha visto antes $/ / /^{\mathrm{APC}}$ os alunos que $/{ }^{\mathrm{COM}}$ praticamente $/{ }^{\mathrm{INX}}$ estavam ignorados $/{ }^{\mathrm{COMel}}$ ali no canto / $\mathrm{APC}$ eh / principalmente depois da reorganização do espaço / $/ \mathrm{APC}$ a questão de ta / cobrando / ${ }^{\mathrm{COMel}}$ de ta mais próximo deles / ${ }^{\mathrm{COMel}}$ né $/ /^{\mathrm{AUX}} \mathrm{e} / /^{\mathrm{INP}}$ alguns alunos envolveram $/{ }^{\mathrm{COM}}$ de alguma forma $/ /^{\mathrm{INX}} /$ não $/ /^{\mathrm{COM}}$ né $/ /^{\mathrm{FAT}}$ de forma que todo professor espera //COM mas ${ }^{\mathrm{AUX}}$ / foi bastante positivo //COM cê sentir que o aluno pelo menos num tá morto $/{ }^{\mathrm{COM}} \mathrm{em}$ relação a língua $/{ }^{\mathrm{APC}}$ né $/ /^{\mathrm{AUX}}$ 


\section{Algumas observações}

Apesar do tamanho reduzido dos excertos apresentados, é possível fazer algumas considerações sobre as características da fala dos dois informantes quanto à estrutura prosódica e informacional. A evidente diferença na dimensão dos turnos é devida ao fato de que a segunda informante organiza as respostas em trechos mais longos, nos quais aparece, mesmo sem grande desenvolvimento, um caráter narrativo ou argumentativo; a isso se deve uma complexidade locutiva ausente nas respostas do primeiro informante. Isso se explica através dos diferentes papéis dos informantes na sociedade e na pesquisa.

Na primeira interação temos 11 enunciados, dos quais dois interrompidos, em 23 segundos, com uma média de pouco mais de 2 segundos por enunciado. Os 23 enunciados são distribuídos em 4 turnos de Vitor e 3 de Gabriel. As unidades tonais e informacionais são, no total, 17, com uma média de pouco mais de 1,5 unidade por enunciado e pouco mais de 1,3 segundos por unidade. Dos 11 enunciados, 6 são simples, ou seja, formados apenas por uma unidade de comentário. Das 17 unidades, 11 são de comentário.

Na segunda interação temos 7 enunciados em 46 segundos, todos no mesmo turno. Note-se que o turno mencionado é apresentado apenas parcialmente. Isso significa uma média de mais de 6,5 segundos por enunciado. As unidades tonais e informacionais são, no total, 38, com uma média de mais de 5,4 unidades por enunciado e pouco mais de 1,2 segundo por unidade. Dos 7 enunciados, apenas os dois primeiros são simples. Das 38 unidades, apenas 12 são de comentário, sendo que aparecem enunciados com mais de um comentário.

Os turnos longos geram, portanto, enunciados muito mais longos e muito mais complexos. É interessante também notar que o princípio ilocucionário é extremamente claro em toda a primeira interação. A segunda, inicialmente, mantém a mesma evidência ilocucionária da primeira, para depois partir para uma construção textual que deixa menos evidente o princípio ilocucionário, apesar de ele ainda ser bem claro. Isso dá uma idéia do que acontece em textos realmente monológicos, nos quais o princípio ilocucionário é bem mais enfraquecido. A progressiva complexificação dos enunciados e o conseqüiente enfraquecimento do princípio ilocucionário são necessários para dar conta de uma complexidade textual motivada por uma locução narrativo-argumentativa. 


\section{Notas}

${ }^{1}$ Uma grande quantidade de textos, entre os quais vários dos que serão citados nesse trabalho, pode ser baixada por meio do site do grupo LABLITA, http://unifi.dit.lablita, coordenado por Emanuela Cresti.

${ }^{2}$ Contrariamente à frase que precisa de intepretabilidade semântica. A frase, portanto, precisa de uma predicação e é interpretável independentemente de um contexto; ao contrário, o enunciado não precisa de verbo, e pode ser constituído apenas por uma interjeção, desde que num contexto em que realize uma ilocução. Um exemplo de enunciado constituído unicamente por uma interjeção é hum hum, em resposta a uma pergunta do tipo Você que é o João?. Nesse contexto, o hum hum é facilmente interpretável como um ato de resposta afirmativa. Mas obviamente o hum hum não poderia nunca constituir uma frase, pois não possui nenhuma interpretabilidade semântica. Para uma exposição aprofundada desses conceitos, vejam-se Cresti (1992, 2001 e 2005).

${ }^{3} \mathrm{~A}$ distinção entre perfis terminais e não terminais não corresponde àquela entre quebras fortes e fracas adotada em trabalhos similares (BUCHMAN et al., 2002).

${ }^{4}$ Para a relação entre a ilocução e a estrutura informacional, veja-se Cresti (1995).

${ }^{5}$ A dupla barra (//) sinaliza o perfil terminal, ou seja, a fronteira de enunciado; a barra simples (/) sinaliza o perfil não terminal, ou seja, a fronteira de unidade tonal e informacional.

${ }^{6}$ Os perfis foram obtidos utilizando-se o software WinPitch de $\mathrm{Ph}$. Martin.

${ }^{7}$ Para a relação entre entonação e unidades informacionais, vejam-se Cresti (1994, 2000b, p. 41-62). Para a articulação tópico-comentário e comentário-apêndice, vejam-se Firenzuoli-Signorini (2003) e Cresti; Firenzuoli (2002).

${ }^{8}$ Em caso de conteúdos locutivos mais longos, é a parte final da curva que carrega o perfil ilocucionário. A análise de corpora de fala espontânea através de parâmetros entonacionais, integrados com outros parâmetros semiológicos e pragmáticos, permitiu a identificação de um repertório de ilocuções do italiano (CRESTI, 2000b, p. 84-116) e a definição de critérios diferentes daqueles propostos em Searle, 1969 (vejam-se CRESTI; MARTIN; MONEGLIA, 1998; CRESTI; FIRENZUOLI, 1999; FIRENZUOLI, 2000a, 2000b, 2003a e 2003b; CRESTI, 2000b).

${ }^{9}$ Tanto a interação 1 quanto a interação 2 apresentam exemplos de tópicos, assim como de apêndices, mas a interação 1 apresenta também sequiências de tópicos. No corpus de italiano foi notada a possibilidade de sequiências de até três tópicos.

${ }^{10}$ A forma entonacional do alocutivo é marcada, mas completamente diferente daquela dos comentários de chamada; não executa um ato de fala, como o comentário de chamada, mas somente uma ativação do canal. 
${ }^{11}$ São unidades tonais compostas por unidades lexicais várias: nomes (força, cuidado, calma), verbos (vai, vão embora, dai) expressões adverbiais (nossa, pô) ou outras, mas sem uma força diretiva interpretável em isolamento.

${ }^{12}$ Para o introdutor locutivo, suas funções, sua forma entonacional e sua relação com o discurso direto, vejam-se Giani (2003a, 2003b, no prelo).

${ }^{13}$ Um elenco, assim como uma comparação ou uma hipótese, por definição, deve ser formado por pelo menos dois componentes.

${ }^{14}$ Alguns exemplos traduzidos de Cresti (2000b, p.159) seriam: eu tinha acabado de chegar / ele já estava morto; encontrou a porta / bum.

${ }^{15}$ A gradação presença/evidência/ausência da força ilocucionária constitui, portanto, um parâmetro importante para estabelecer uma tipologia textual.

${ }^{16}$ Veja-se, para essa questão, Cresti (1997, 2000b, p.163), e o volume sobre o italiano no rádio (AA. VV., 1997).

${ }^{17}$ Os nomes dos informantes e dos pesquisadores são fictícios.

${ }^{18}$ Para a validação da segmentação, foi seguido o procedimento adotado no C-ORALROM, com algumas adaptações contextuais. Para o procedimento, veja-se Moneglia; Scarano; Spinu (http://lablita.dit.unifi.it/coralrom/papers/Validazione\% 202.1.pdf)

\section{Bibliografia}

AA. VV. L'italiano trasmesso: la radio. Firenze: Accademia della Crusca, 1997.

AUSTIN, J. L. How to do things with words. London: Oxford University Press, 1962.

BILGER, M. (Org.). Corpus. Méthodologie et applications linguistiques. Paris: Champion, Bibliothèque de l'INaLF, 2000.

BUCHMAN et al. 2002. Annotation of prominent words, prosodic boundaries and segmental lenghtening by no-expert transcribers in the spoken Dutch corpus. LREC, 2000. p. 779-785.

BURNS, A. Collaborative Action Research for English Language Teachers. Cambridge: Cambridge University Press, 1999.

CRESTI, E. Definizione dell'enunciato e pragmatica. In: BRASCA, L.; ZAMBELLI, L.M. (Org.). Atti del $V^{\circ}$ Convegno nazionale GISCEL. Grammatica del parlare e dell'ascoltare a scuola. Firenze: La Nuova Itália, p. 51-77, 1992.

Information and intonational patterning in Italian. In: FERGUSON, B.; GEZUNDHAJT, H.; MARTIN, Ph. (Org.). Accent, intonation et modèles phonologiques. Toronto: Editions Mélodie, 1994. p. 99-140. 
CRESTI, E. Speech act units and informational units. In: FAVA, E. Speech Acts and Linguistic Research. Proceedings of the Workshop, July 15-17, 1994. Buffalo: Center for Cognitive Science - Padova: Nemo, 1995, p. 89-107.

Confronto tra la 'resa informativa' del dialogo spontaneo e dell'intervista radiofonica. Em: AA. VV., 1997, p. 611-657.

Critère illocutoire et articulation informative. In: BILGER, M. (Org.). Corpus, méthodologie et applications Linguistiques. Paris: Champion, 2000a, p. 350-367.

Corpus di italiano parlato. Firenze: Accademia della Crusca. 2000b, 2 voll. + CDRom.

Per una nuova definizione di frase. In: BONGRALLI, P.; DARDI, A.; FANFANI, M.; TESI, R. (Org.). Studi di storia della lingua italiana offerti a Ghino Ghinassi. Firenze: Le Lettere, p. 511-550, 2001.

Enunciato e frase: teoria e verifiche empiriche. In: BIFFI, M.; CALABRESE, O.; SALIBRA, L. (Org.). Italia Linguistica: discorsi di scritto e di parlato. Scritti in onore di Giovanni Nencioni. Siena: Prolagon, p. 249-260, 2005.

CRESTI, E.; FIRENZUOLI, V. Illocution et profils intonatifs de l'italien. Revue française de Linguistique appliquée, IV, p. 77-98, 1999.

. L'articolazione informativa topic-comment e comment-appendice: correlati intonativi. In: REGNICOLI, A. (Org.). La fonetica acustica come strumento di analisi della variazione linguistica in Italia. Atti delle XII Giornate del Gruppo di Fonetica Sperimentale (XII GFS). Roma: Il Calamo, 2002, p. 153-160.

CRESTI, E.; MARTIN, P.; MONEGLIA, M. L'intonazione delle illocuzioni naturali rappresentative: analisi e validazione percettiva. In: DELMONTE, R. (Org.). Atti delle IX giornate del gruppo di fonetica sperimentale (AIA). Padova: Unipress, 1998. p. 51-63.

CRESTI, E.; MONEGLIA, M. (Org.). C-ORAL-ROM. Integrated Reference Corpora for Spoken Romance Languages. Amsterdam-New York: Johns Benjamins, $2005+$ DVD.

CRESTI, E.; SCARANO, A. Sur la notion de parlé spontané. In: BILGER, M. (Org.), 2000, p. 340-349.

FIRENZUOLI, V. Ordine e istruzione-Espressione di incredulità e contrasto. Descrizione di profili intonativi dal corpus di italiano parlato LABLITA. In: LOCCHI, D. (Org.). Il parlante e la sua lingua. Atti delle $X$ giornate di studio del gruppo di fonetica sperimentale (AIA). Napoli: Istituto Orientale, 2000a. p. 99-110. 
FIRENZUOLI, V. Metodologie sperimentali per l'identificazione di profili intonativi di valore illocutivo a partire dal corpus LABLITA. In: Atti del VI Convegno SILFI. Duisburg: Università di Duisburg, 2000b.

Le forme intonative di valore illocutivo dell'italiano parlato: analisi sperimentale di un corpus di parlato spontaneo. $\mathrm{PhD}$ thesis: Università degli Studi di Firenze, 2003a.

Verso un approccio allo studio dell'intonazione a partire da corpora di parlato: esempi di profili intonativi di valore illocutivo dell'italiano. In: MARASCIO, N. Atti del XXXIV Congresso internazionale di studi della SLI "Italia linguistica anno Mille - Italia linguistica anno Duemila”. Roma: Bulzoni, p. 535-550, 2003 b.

FIRENZUOLI, V.; SIGNORINI, S. L'unità informativa di topic: correlati intonativi. In: Atti delle giornate del gruppo di fonetica sperimentale (XIII GFS). Pisa: ETS, 2003. p. 177-184.

FIRENZUOLI, V.; TUCCI, I. L'unità informativa di inciso: correlati intonativi. In: Atti delle XIII giornate del gruppo di fonetica sperimentale. Pisa: ETS, 2003. p. 185-194.

GIANI, D. Le discours direct rapporté dans l'italien parlé et écrit. In: SCARANO, A. Macro-Syntaxe et Pragmatique. L'analyse Linguistique de l'Oral. Roma: Bulzoni, 2003a.

. Il verbo "dire" nell'italiano parlato: articolazione informativa e sintassi. In: GIACOMO-MARCELLESI, M. (Org.). Atti del XXXV Congresso Internazionale di Studi della Società di Linguistica Italiana (SLI). Roma: Bulzoni, 2003b.

Una strategia di costruzione del testo parlato: l'introduttore locutivo. In: Atti del Convegno "Il parlato italiano". No prelo.

t'HART, J.; COLLIER, R.; COHEN, A. A perceptual study on intonation. An experimental approach to speech melody. Cambridge: Cambridge University Press: 1990.

MARTIN, Ph., WinPitch <www.winpitch.com>.

MONEGLIA, M.; SCARANO, A.; SPINU, M. Validation by expert trascribers of the C-ORAL-ROM tagging criteria on Italian, Spanish e Portuguese corpora of spontaneous speech. Disponível em: (http://lablita.dit.unifi.it/coralrom/papers/ Validazione\%202.1.pdf)

TUCCI, I. L'inciso: caratteristiche morfosintattiche e intonative in un corpus di riferimento. In: Atti del Convegno "Il parlato italiano". No prelo. 